\title{
Multiple Modes of Synaptic Excitation of Olfactory Bulb Granule Cells
}

\author{
Ramani Balu, R. Todd Pressler, and Ben W. Strowbridge \\ Department of Neurosciences, Case Western Reserve University, Cleveland, Ohio 44106
}

\begin{abstract}
Inhibition generated by granule cells, the most common GABAergic cell type in the olfactory bulb, plays a critical role in shaping the output of the olfactory bulb. However, relatively little is known about the synaptic mechanisms responsible for activating these interneurons in addition to the specialized dendrodendritic synapses located on distal dendrites. Using two-photon guided minimal stimulation in acute rat brain slices, we found that distal and proximal excitatory synapses onto granule cells are functionally distinct. Proximal synapses arise from piriform cortical neurons and facilitate with paired-pulse stimulation, whereas distal dendrodendritic synapses generate EPSCs with slower kinetics that depress with paired stimulation. Proximal cortical feedback inputs can relieve the tonic Mg block of NMDA receptors (NMDARs) at distal synapses and gate dendrodendritic inhibition onto mitral cells. Most excitatory synapses we examined onto granule cells activated both NMDARs and AMPA receptors, whereas a subpopulation appeared to be NMDAR silent. The convergence of two types of excitatory inputs onto GABAergic granule cells provides a novel mechanism for regulating the degree of interglomerular processing of sensory input in the olfactory bulb through piriform cortex/olfactory bulb synaptic interactions.
\end{abstract}

Key words: olfactory bulb; GABA; granule cell; mitral cell; synapse; piriform cortex; plasticity

\section{Introduction}

In many brain regions, local circuits form the fundamental building blocks that enable neuronal computation. In the olfactory bulb (OB), locally generated inhibitory synaptic interactions play a central role in shaping mitral and tufted cell responses to sensory stimuli (Hamilton and Kauer, 1985, 1989). Although the dendritic arborization of granule cells is relatively small (50-200 $\mu \mathrm{m})$ (Shepherd and Greer, 1998), a single granule cell may receive synaptic inputs from mitral cells several millimeters away (Shepherd and Greer, 1998), providing a theoretical basis for massive synaptic divergence. In vivo recordings, however, suggest that unlike glutamatergic mitral cells, inhibitory granule cells are only weakly activated after sensory stimulation (Cang and Isaacson, 2003). These findings raise the possibility that the pattern of interneuronal activation, and thus lateral inhibition onto principal cells, is not regulated predominately by dendrodendritic synaptic inputs but instead may reflect the temporal coincidence of several types of synaptic inputs to granule cells.

Granule cells receive two anatomically distinct classes of excitatory input on their proximal and distal dendrites (see Fig. 1A). Reciprocal dendrodendritic synapses with mitral cells are the primary distal source of excitatory input (Rall et al., 1966; Price and Powell, 1970a,b). Granule cell activation through distal dendrodendritic synapses, however, depends on NMDA receptors,

Received 0ct. 25, 2006; revised April 18, 2007; accepted April 19, 2007.

This work was supported by National Institutes of Health Grants DC04825 and NS33590 (B.W.S.). R.B. received support from National Research Service Award Fellowship DC007274. We are grateful to C. J. Frazier, L. T. Landmesser, and M. de Curtis for constructive comments on this manuscript.

Correspondence should be addressed to Dr. Ben W. Strowbridge, Department of Neurosciences, Case Western Reserve University, 10900 Euclid Avenue, Cleveland, 0H 44106. E-mail: bens@case.edu.

DOI:10.1523/JNEUROSCI.4630-06.2007

Copyright $\odot 2007$ Society for Neuroscience $\quad$ 0270-6474/07/275621-12\$15.00/0 which are tonically blocked by extracellular $\mathrm{Mg}$ ions (Isaacson and Strowbridge, 1998; Schoppa et al., 1998; Chen et al., 2000). Tetanic stimulation of axons in the granule cell layer (GCL) not only activates granule cells but also relieves the $\mathrm{Mg}$ blockade of NMDA receptors at distal dendrodendritic synapses (Halabisky and Strowbridge, 2003). These results suggest that the proximal excitatory inputs to granule cells may play an important role in gating recurrent and lateral dendrodendritic inhibition (DDI) in the olfactory bulb. However, the primary source of these proximal excitatory inputs is unclear; previous studies have suggested that both mitral cell axon collaterals (Price and Powell, 1970b; Orona et al., 1984) and centrifugal cortical axons (de Olmos et al., 1978; Haberly and Price, 1978; Shipley and Adamek, 1984) innervate granule cells at proximal synapses.

The explanation for the selective ability of gamma frequency stimuli, and not single stimuli or lower frequency trains, to gate dendrodendritic inhibition (Halabisky and Strowbridge, 2003) also is unclear. Presumably, this relates to specific forms of shortterm plasticity (facilitation or depression) at proximal excitatory synapses on granule cells. The one study that addressed shortterm plasticity in granule cells (Dietz and Murthy, 2005) found evidence for both facilitating and depressing excitatory synapses onto granule cells. However, it is not clear whether individual granule cells receive different types of excitatory input or whether this heterogeneity reflects multiple functionally defined subpopulations of granule cells.

In this study, we defined the functional properties and shortterm plasticity in the two known types of excitatory synapses onto granule cells in the rat olfactory bulb. Using two-photon guided minimal stimulation (2PGMS), we found that proximal axodendritic and distal dendrodendritic excitatory synapses form two homogeneous classes of inputs that have different kinetics and 
different forms of short-term plasticity. These results suggest that inhibition onto mitral cells is governed by the relative timing of two independent excitatory inputs to granule cells: distal dendrodendritic synapses with the mitral cell secondary dendrites and proximal inputs from cortical pyramidal cells that project back to the olfactory bulb.

\section{Materials and Methods}

Slice preparation and recording. Horizontal slices $(300 \mu \mathrm{m})$ through the olfactory bulb or ventral hippocampus were prepared from anesthetized (ketamine, $140 \mathrm{mg} / \mathrm{kg}$, i.p.) postnatal day 10 (P10) to P21 Sprague Dawley rats using a modified Leica (Nussloch, Germany) VT1000S vibratome, as described previously (Isaacson and Strowbridge, 1998; Halabisky et al., 2000; Halabisky and Strowbridge, 2003). An artificial CSF (ACSF) dissection solution with reduced Ca was used when preparing and storing slices. This solution contained the following (in $\mathrm{mm}$ ):124 $\mathrm{NaCl}, 2.6 \mathrm{KCl}, 1.23 \mathrm{NaH}_{2} \mathrm{PO}_{4}, 3 \mathrm{MgSO}_{4}, 26 \mathrm{NaHCO}_{3}, 10$ dextrose, and 1 $\mathrm{CaCl}_{2}$, equilibrated with $95 \% \mathrm{O}_{2} / 5 \% \mathrm{CO}_{2}$ and chilled to $4^{\circ} \mathrm{C}$ during slicing. For experiments investigating cortical feedback projections, we made larger horizontal slices including both the olfactory bulb and a section of anterior piriform cortex (APC). Combined olfactory bulb/ piriform cortex slices were prepared by attaching the ventral surface of a block of brain tissue containing both olfactory bulbs and frontal lobes to the vibratome stage. Horizontal slices prepared from this block at least $1.5 \mathrm{~mm}$ from the ventral surface contained both the olfactory bulb and a portion of the anterior piriform cortex. Some slices also included some of the anterior olfactory nucleus (AON) located medial to the piriform cortex. In slices, we first identified the AON/piriform cortex boundary to ensure that all stimulation and dye injection sites were confined to the piriform cortex and did not include the AON. Anterior piriform cortex was readily identified by its lateral location, laminated structure, and cellular morphology using infrared-differential interference contrast (IR-DIC) microscopy. Hippocampal slices were prepared as described previously (Frazier et al., 2003).

Brain slices were incubated in a $30^{\circ} \mathrm{C}$ water bath for $30 \mathrm{~min}$ and then maintained at room temperature. During experiments, slices were superfused with ACSF at room temperature that contained the following (in mm): $124 \mathrm{NaCl}, 3 \mathrm{KCl}, 1.23 \mathrm{NaH}_{2} \mathrm{PO}_{4}, 1.2 \mathrm{MgSO}_{4}, 26 \mathrm{NaHCO}_{3}, 10$ dextrose, and $2.5 \mathrm{CaCl}_{2}$, equilibrated with $95 \% \mathrm{O}_{2} / 5 \% \mathrm{CO}_{2}$. Whole-cell patch-clamp recordings were made from mitral and granule cells in the olfactory bulb and CA1 hippocampal pyramidal neurons visualized under IR-DIC optics using an BX51WI fixed-stage upright microscope (Olympus, Center Valley, PA) and an Axopatch 1D amplifier (Molecular Dynamics, Sunnyvale, CA). Patch electrodes used for granule and hippocampal cell voltage-clamp recordings (5-7 $\mathrm{M} \Omega$ resistance) contained the following (in $\mathrm{mm}$ ): 115 Cs-methanesulfonate, $4 \mathrm{NaCl}, 25$ tetraethylammonium-methanesulfonate, $5 \mathrm{~N}$-ethyl bromide quaternary salt (QX-314), 10 HEPES, 1 EGTA, 4 MgATP, $0.3 \mathrm{Na}_{3} \mathrm{GTP}$, and 10 phosphocreatine. The same internal solution was used for the mitral cell recordings in the dendrodendritic inhibition experiments shown in Figure 6. For experiments investigating hippocampal silent synapses and long-term potentiation, we evoked EPSCs onto single CA1 pyramidal cells through Schafer collateral inputs using a glass monopolar stimulating electrode filled with HEPES buffered saline (124 mM NaCl, $3 \mathrm{~mm} \mathrm{KCl}$, $10 \mathrm{~mm}$ HEPES, $\mathrm{pH}$ adjusted to 7.4) placed in the stratum radiatum connected to a constant current stimulus isolation unit (World Precision Instruments, Sarasota, FL). In most experiments, $100 \mu \mathrm{M}$ Alexa594 was added to the pipette solution to visualize neuronal morphology. In other experiments, $150 \mu \mathrm{M}$ Oregon Green BAPTA-1 (OGB-1) was added to the patch solution in place of EGTA to visualize synaptically evoked calcium transients. All granule cell recordings were obtained in the presence of gabazine $(10 \mu \mathrm{M})$ to block $\mathrm{GABA}_{\mathrm{A}}$ receptor-mediated synaptic events. All chemicals were obtained from Sigma (St. Louis, MO) except for Alexa 594 hydrazide and Oregon Green 488 BAPTA1 hexapotassium salt (Invitrogen, Eugene, OR).

Two-photon imaging. Live imaging experiments used a custom twophoton microscope based on the Verdi V10 pump laser, Mira 900 Tisapphire laser (both from Coherent, Santa Clara, CA) and a high-speed
XY galvanometer mirror system (6210; Cambridge Technology, Lexington, MA). Intracellularly loaded fluorescent dyes were excited at $830 \mathrm{~nm}$ through a $60 \times$ water-immersion objective (Olympus). Emitted light was detected through an epifluorescent light path that included a 700DCLPXR dichroic mirror, a BG39 emission filter (both from Chroma Technology, Rockingham, VT), and a cooled photomultiplier tube detector module (H7422P-40; Hamamastu, Bridgewater, NJ). Photomultiplier output was converted into an analog voltage by a high-bandwidth current preamplifier (SR-570; Stanford Research Systems, Sunnyvale, CA). Custom Visual Basic software written by B.W.S. controlled the scanning system and image analysis functions. Laser beam intensity was controlled electronically through a Pockels cell attenuator (ConOptics, Danbury, CT) and a Uniblitz shutter (Vincent Associates, Rochester, $\mathrm{NY}$ ). In most experiments, the output of the Mira laser was attenuated by 90-95\%.

Two-photon guided stimulation. We used two-photon microscopy to guide the focal stimulation of different populations of excitatory inputs on granule cells. After waiting for 10-15 min to allow the dye to diffuse from the patch pipette into distal processes, we used a fast scanning mode (3200 lines/s) to visualize granule cell morphology and spines. We then placed a glass stimulating pipette (tip opening, $\sim 1 \mu \mathrm{m}$ ) containing HEPES buffered saline ( $124 \mathrm{~mm} \mathrm{NaCl}, 3 \mathrm{~mm} \mathrm{KCl}, 10 \mathrm{~mm}$ HEPES, 50-100 $\mu \mathrm{M}$ Alexa 594, $\mathrm{pH}$ adjusted to 7.4$) \sim 10-30 \mu \mathrm{m}$ away from distal spines located in the external plexiform layer (EPL) or proximal spines located in the granule cell layer under two-photon guidance. This stimulating electrode was connected to a constant-current stimulus isolation unit (World Precision Instruments) and used to evoke neurotransmitter release from presynaptic terminals located near granule cell dendrite segments of interest. We used two-photon Ca imaging in some experiments to confirm that this focal stimulation method reliably activated spines near the stimulating electrode. Subsequent experiments using glutamate receptor antagonists (see Fig. $3 A$ ) confirmed that these spines were activated synaptically and not by passive depolarization from the stimulating electrode. We used two-photon imaging to position Alexa 594-filled pipettes near visualized dendritic segments for both minimal and supraminimal stimulation experiments. We evoked supraminimal responses by increasing the stimulus intensity until there were no failures, and the response amplitude was approximately twice the amplitude of successes evoked by minimal stimulation (typically two to three times the intensity used for minimal stimulation in the same experiment).

Imaging synaptically evoked calcium transients. To image synaptically evoked calcium transients, we filled granule cells voltage clamped at -70 $\mathrm{mV}$ with $150 \mu \mathrm{M}$ OGB-1. After waiting for 15-20 min to allow the dye to diffuse into distal processes, we placed an Alexa 594-filled stimulating pipette near a group of granule cell spines (see above) to evoke neurotransmitter release onto spines of interest. Calcium transients were imaged by taking sequential images in a fast-scanning mode $(25 \mathrm{~ms}$ frame rate, 3200 lines/s) during extracellular stimulation and then calculating the percentage change in fluorescence over baseline. Regions of interest were placed over dendrites and spines to calculate changes in dendritic and spine calcium levels, respectively. For these experiments, we used a Mg-free ACSF to maximize calcium influx through NMDA receptors (Isaacson and Strowbridge, 1998).

DiI injections. To visualize the trajectory of cortical axons as they entered the olfactory bulb, we injected a bolus of $\mathrm{DiIC}_{18}(3)$ (3 mM in ethanol) into the anterior piriform cortex using a patch pipette connected to a picospritzer (2 psi, $500 \mathrm{~ms})$ in combined olfactory bulb/piriform cortex slices. After recording, slices were fixed in PBS containing 4\% paraformaldehyde overnight at $4^{\circ} \mathrm{C}$. Fixed slices were then placed in PBS and kept at room temperature for 2 weeks to allow DiI to diffuse through axonal processes. To visualize DiI-labeled processes, slices were wholemounted onto microscope slides, coverslipped, and imaged using epifluorescence microscopy (Axioskop 2; Carl Zeiss, Thornwood, NY). Fluorescent images were digitized using an DP70 CCD camera (Olympus).

Data acquisition and analysis. Electrophysiological data were recorded and analyzed using custom software written in Visual Basic 6 (Microsoft, Redmond, WA) and Origin 7.5 (OriginLab, Northhampton, MA). Current and voltage records were low-pass filtered at $2 \mathrm{kHz}$ and then digitized at $5 \mathrm{kHz}$ using a 16-bit A/D converter (ITC-18; Instrutech, Port 
A

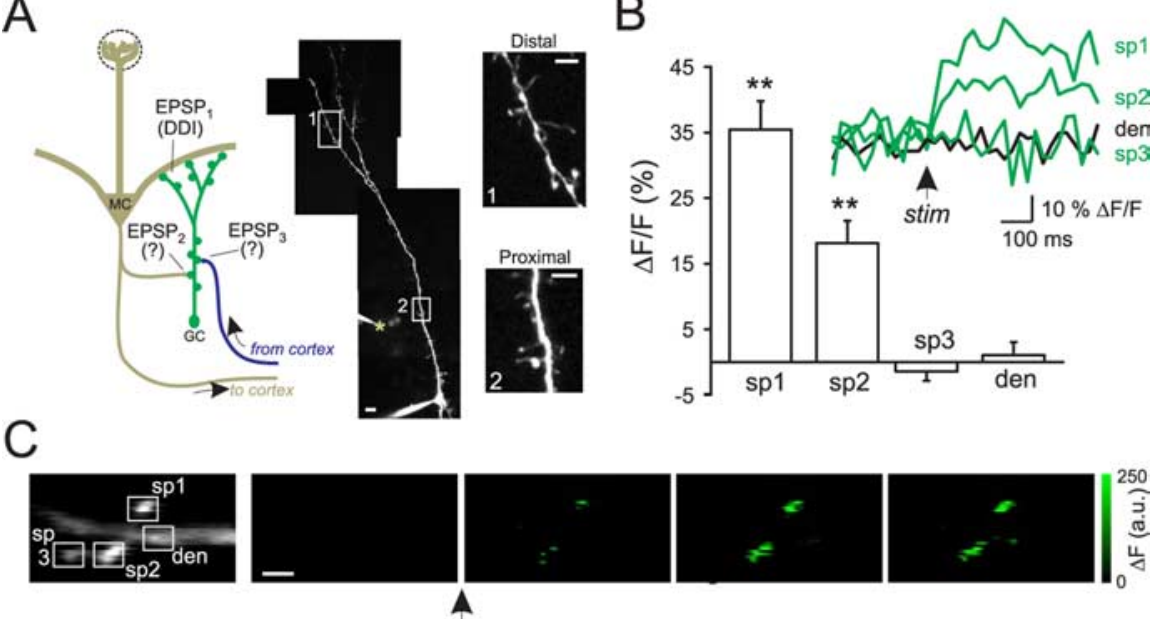

$D_{1}$
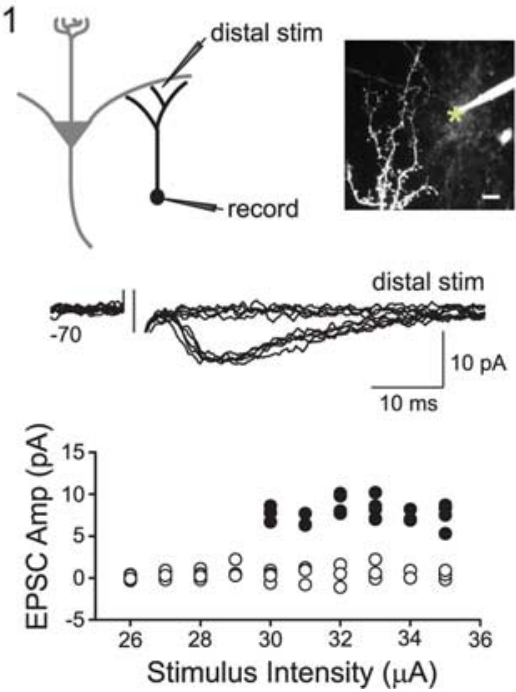

$\mathrm{D}_{2}$
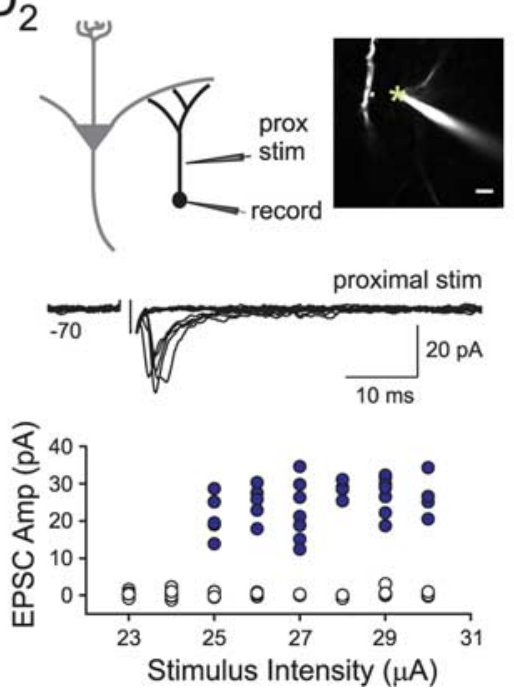

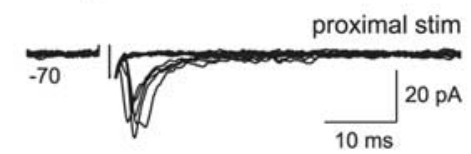

Figure 1. Two classes of spontaneous EPSCs in granule cells. $\boldsymbol{A}$, Schematic diagram of excitatory synapses onto granule cells. Tw0-photon reconstruction of an Alexa 594-filled granule cell shown on the right. A second patch pipette containing Alexa 594 was used for extracellular stimulation and is visible near the apical dendrite. The stimulating electrode tip is indicated by a tan asterisk. Insets show magnified views of granule cell dendrites with spines located on both distal bifurcated dendrites in the EPL (top) and the proximal primary dendrite (bottom). Scale bars: full reconstruction, $10 \mu \mathrm{m}$; insets, $5 \mu \mathrm{m}$. B, Plot of 0GB-1 Ca transients recorded over six trials in the three spines (sp1, sp2, and sp3) and a dendrite shaft segment (den). Focal supraminimal stimuli (single $200 \mu$ s shock, $43 \mu$ A; Alexa 594-filled stimulating electrode positioned $\sim 20 \mu \mathrm{m}$ from imaged dendritic region) reliably triggered Ca accumulations in two of the three imaged spines (sp1 and sp2) but not in the dendritic shaft segment. Statistically significant increases over baseline are indicated by asterisks $\left({ }^{* *} p<0.01\right)$. Inset, Example $\Delta F / F$ traces from one trial. $C$, Twophoton images of baseline $0 G B-1$ fluorescence (left) and $\Delta F$ image frames before and immediately after a single focal stimulus. Stimulus-evoked $C$ a accumulations were restricted to a subset of imaged dendritic spines. Labeled regions of interest correspond to image areas analyzed in $\boldsymbol{B}$. Acquired images were 392 by 64 pixels; $25 \mathrm{~ms} /$ frame. Scale bar, $3 \mu \mathrm{m}$. D, Plots of amplitudes of unitary EPSCs evoked by two-photon guided minimal stimulation (stim) of distal $\left(\boldsymbol{D}_{1}\right)$ and proximal (prox) $\left(\boldsymbol{D}_{2}\right)$ granule cell dendrites versus stimulus intensity. Insets show two-photon images of the relationship between the distal stimulating electrode in the EPL and the proximal stimulating in the $\mathrm{GCL}$ and the recorded granule cells. Both recording and stimulating pipettes were filled with Alexa 594. The stimulating electrode tip is indicated by a tan asterisk. Scale bar: Left, $10 \mu \mathrm{m} ;$ right, $7 \mu \mathrm{m}$. Distal minimal stimulation evoked all-or-none EPSCs with slow-rising phases, whereas proximal minimal stimulation evoked fast-rising EPSCs. Both distal and proximal stimulation responses show sharp activation thresholds with distinguishable successes (filled circles) and failures (open circles). Example threshold responses are shown above each plot.

Washington, NY). Series resistance was typically $<20 \mathrm{M} \Omega$ and was routinely compensated by $>80 \%$ in voltage-clamp experiments.

Evoked EPSCs were detected by the first derivative (slope threshold, 3 $\mathrm{pA} / \mathrm{ms}$ ) using custom software written in Visual Basic 6 and verified by visual inspection. EPSC amplitudes were measured by calculating the average value during a $1 \mathrm{~ms}$ window surrounding the peak relative to the average baseline value in a $5 \mathrm{~ms}$ window immediately before the stimulus. The peak time was measured by calculating the time point when the first derivative crossed from negative to positive. Evoked responses were cat- egorized as failures if the threshold for slope change was not reached in a $20 \mathrm{~ms}$ window after the stimulus. EPSC amplitude was measured as the average value during a $1 \mathrm{~ms}$ window $10 \mathrm{~ms}$ after the stimulus relative to the average baseline value immediately before the stimulus. The $10-90 \%$ rise times were calculated by subtracting the time after EPSC onset to reach $90 \%$ of the peak value from the time to reach $10 \%$ of the peak value. Failure rates were calculated by dividing the number of trials with no slope change by the total number of responses. In a subset of neurons, we verified this method by also calculating failure rate by first measuring the EPSC amplitude for all trials in a $1 \mathrm{~ms}$ time window $10 \mathrm{~ms}$ after the stimulus onset, doubling the number of responses with amplitude $>0 \mathrm{pA}$ and dividing by the total number of trials (Liao et al., 1995). These two methods did not show any significant differences. To provide a visual estimate of the proportion of failures, we included dashed vertical lines at two times the noise SD in the amplitude histograms in Figure $7 B$.

In the minimal stimulation experiments, we assumed activation of a single presynaptic axon or dendrite if we observed: (1) all-or-none EPSCs, that (2) gradually increasing stimulus intensity resulted in an abrupt transition from all failures to all-or-none responses, and that (3) small changes in the stimulus intensity beyond that threshold had no change in the amplitude of successes. For these experiments, we calculated paired-pulse ratios (PPRs) by measuring both the ratio of average EPSC amplitudes (both failures and successes) and by calculating the ratio of quantal contents estimated by failure rates (del Castillo and Katz, 1954; Isaacson, 1995). We typically analyzed 50-150 trials for each cell. For supraminimal stimulation experiments, the paired-pulse ratio was measured by averaging 10-20 trials and calculating the ratio of average EPSC amplitudes. Data are presented as mean \pm SEM. Unless otherwise noted, statistical significance was determined using Student's $t$ test.

\section{Results}

Two distinct classes of excitatory inputs onto granule cells

Olfactory bulb granule cells form two morphologically distinct spines that are spatially segregated along the dendritic tree: large gemmules in the EPL that are the sites of reciprocal dendrodendritic synapses and spines that are purely postsynaptic along the proximal apical and basal dendrites in the GCL (Price and Powell, 1970a; Shepherd and Greer, 1998). We used 2PGMS to selectively activate the presynaptic processes that contact these two types of granule cell spines. In most of these experiments, both the granule cell recorded under voltage clamp and the focal stimulating electrode were filled with Alexa 594 and visualized using two-photon microscopy. We positioned the stimulating pipette near a visualized dendritic segment to selectively activate distal (in the EPL) or proximal (in the GCL) excitatory synaptic inputs (Fig. 1A). Using this method, we could 
A

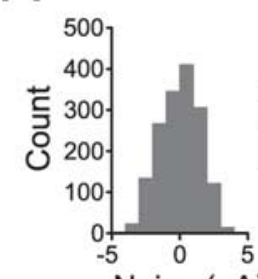

B

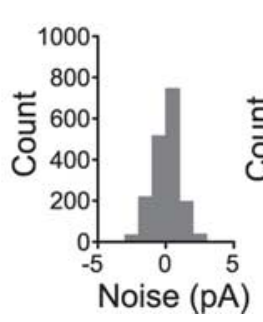

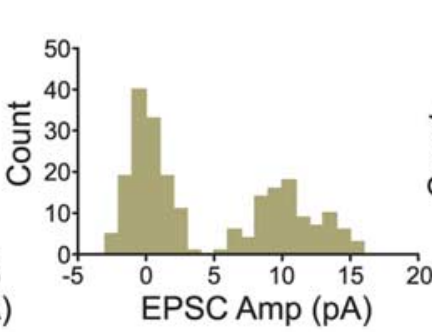
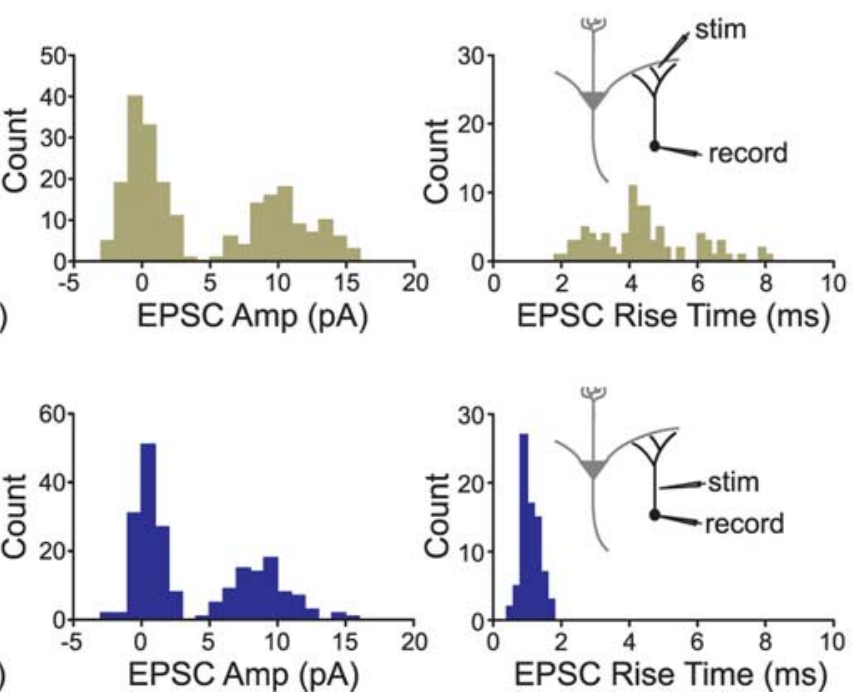

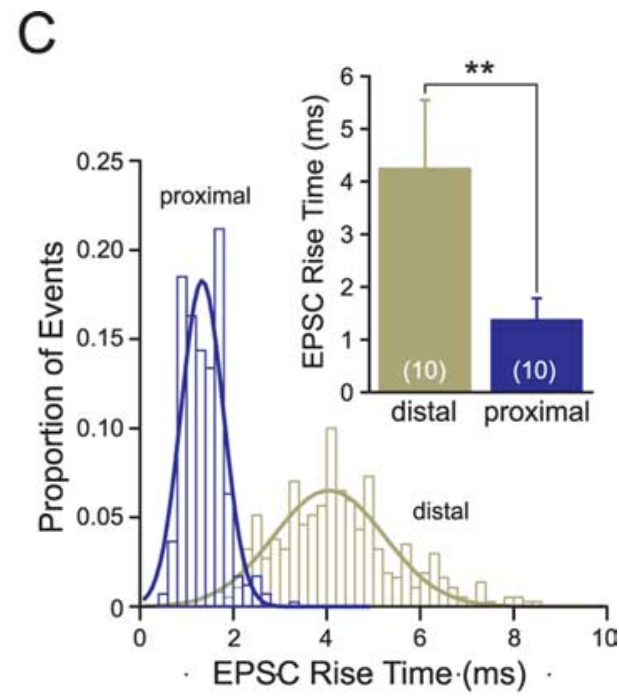

Figure 2. Kinetic differences between distal and proximal minimal EPSCs. $\boldsymbol{A}, \boldsymbol{B}$, Amplitude (middle) and rise time (right) EPSC distributions calculated from distal ( $\boldsymbol{A}$, gold) and proximal ( $\boldsymbol{B}$, purple) two-photon guided minimal stimulation. Inset shows relative position of the stimulating electrode (stim). Data from two different granule cells held at $-70 \mathrm{mV}$. Distribution of failures in the amplitude plots closely matches the noise amplitude distribution calculated from the same cells (left). Note the different EPSC rise time distributions between responses evoked from the two stimulus positions. C, Summary plot of the rise time distribution from all distal ( $n=10$ cells; gold) and proximal ( $n=10$ cells; purple) stimulation experiments. Both distributions were well fit by Gaussian distributions (smooth curves). The inset shows statistically significant difference in mean EPSC rise time for the two stimulation sites $\left({ }^{* *} p<0.01\right)$.

perform minimal stimulation to activate single presynaptic terminals and evoke unitary, all-or-none postsynaptic events. Increasing the stimulus intensity allowed us to evoke transmitter release from a localized group of presynaptic terminals near the stimulus electrode (supraminimal stimulation). To verify that this method effectively activated spines near the stimulating pipette, we first conducted a series of experiments with granule cells filled with $150 \mu \mathrm{M}$ OGB-1 instead of Alexa 594. As shown in Figure 1, $B$ and $C$, supraminimal stimulation $(200 \mu \mathrm{s}, 43 \mu \mathrm{A}$; single shock) using this technique selectively triggered $\mathrm{Ca}$ influxes in two of three imaged proximal dendritic spines that were near $(\sim 20 \mu \mathrm{m})$ the stimulation pipette. At this stimulus intensity, no $\mathrm{Ca}$ accumulation was detected in the third spine or in neighboring dendrite shaft, suggesting that the nearby spines were activated by synaptic inputs and not by passive depolarization from the stimulating electrode. We also show below that glutamate receptor antagonists (NBQX and D-APV) completely block the electrical response of granule cells to this form of focal stimulation. This localized pattern of $\mathrm{Ca}$ accumulation was repeatable across multiple trials (Fig. $1 B$ ), suggesting that this stimulation protocol reliably evoked neurotransmitter release from a localized group of presynaptic terminals near the stimulating electrode. We observed similar results showing Ca transients in subsets of spines near the stimulating pipette and the absence of $\mathrm{Ca}$ accumulations in dendritic shafts, with both proximal and distal two-photon guided stimulation ( $n=4$ cells).

Using 2PGMS with both the recording and stimulating electrodes filled with Alexa 594, weak focal stimuli evoked unitary EPSCs at both distal (Fig. $1 D_{1}$ ) and proximal (Fig. $1 D_{2}$ ) stimulus sites in an all-or-none manner. Both stimulus sites showed abrupt response thresholds above which unitary responses (successes) could be clearly distinguished from failures. Although the unitary response amplitude was relatively constant after small increases in stimulus intensity in each cell, response amplitudes were variable across the population of cells tested (mean unitary amplitude: $-21.9 \pm 1.7 \mathrm{pA}, n=10$ cells for proximal, $-10.6 \pm$ $0.7 \mathrm{pA}, n=10$ cells for distal 2PGMS). As expected, unitary responses evoked by 2PGMS near proximal dendritic locations showed little latency jitter [mean latency jitter (SD), $1.09 \pm 0.05$ $\mathrm{ms} ; n=10$ cells $]$. In contrast, most responses evoked at distal sites showed increased jitter (mean latency jitter, $2.29 \pm 1.0 ; n=10$ cells; significantly different from the SD of proximal 2PGMS response latencies; $p<0.01)$. The homogenous nature of the distal 2PGMS responses, the relatively low stimulus intensities used in these experiments, and the absence of any anatomical evidence for recurrent excitatory pathways in the external plexiform layer (Schoppa and Urban, 2003) are all consistent with the monosynaptic responses. The origin of this distal EPSC latency jitter may reflect biophysical differences (e.g., possibly lower $\mathrm{Na}$ channel densities and longer membrane time constants) in presynaptic dendritic compartments, compared with presynaptic axon segments. Theoretically, brief (100-200 $\mu \mathrm{s})$ extracellular stimuli should more efficiently excite thin neuronal structures with small chronaxies, such as axons, than larger-diameter dendrites (Ranck, 1975).

Unitary EPSCs evoked by proximal and distal 2PGMS had different kinetics. The rise time distribution for proximally evoked EPSCs (Fig. 2A) was smaller than the analogous plot for EPSCs evoked by distal 2PGMS (Fig. $2 B$ ). Figure $2 C$ shows the overall rise time distribution for 10 granule cells with distal and 10 different granule cells with proximal 2PGMS. Across our population of granule cell recordings, the mean distal 2PGMS EPSC rise time $(4.20 \pm 1.3 \mathrm{~ms} ; n=10)$ was significantly greater than the proximal EPSC rise time $(1.36 \pm 0.42 \mathrm{~ms} ; n=10 ; p<0.01)$.

\section{Distal and proximal excitatory synapses are functionally distinct}

Synaptic responses with different kinetics may arise from multiple mechanisms. Differences in EPSC kinetics may reflect different positions of activated synapses along the dendritic tree, generating different degrees of electrotonic attenuation, or they may reflect biophysical differences between different types of synapses, or a combination of these two mechanisms. We used paired-pulse stimulation to determine whether the differences 
$A_{1}$

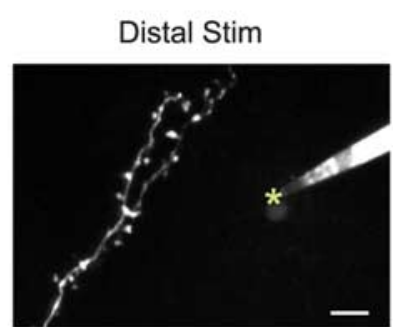

Minimal

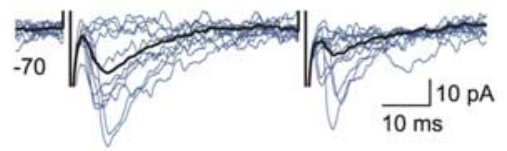

Supraminimal

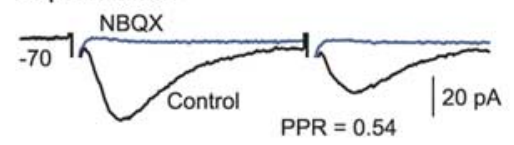

$\mathrm{B}_{1}$
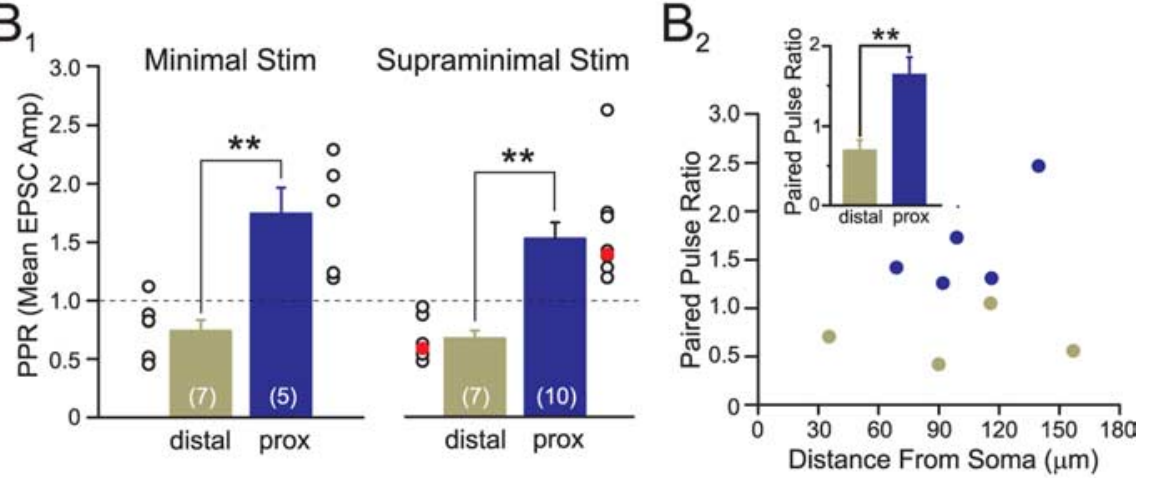

C

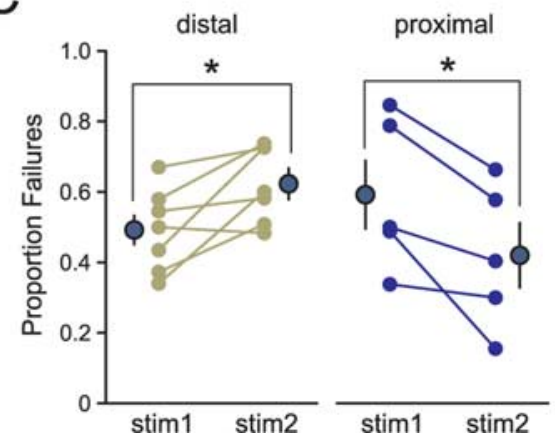

D

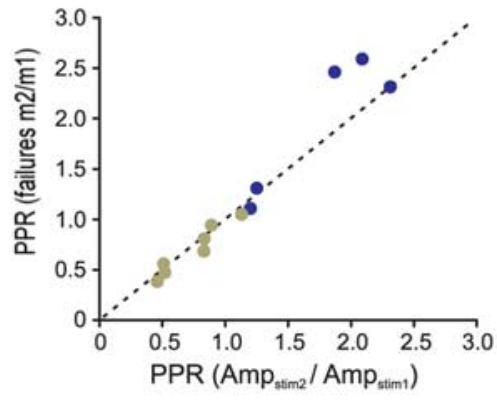

Figure 3. Distal and proximal excitatory synapses have different forms of short-term plasticity. $A$, Granule cell responses to two-photon guided paired-pulse stimulation (stim) $(50 \mathrm{~ms} \mid \mathrm{SI})$ of either distal $\left(\boldsymbol{A}_{\boldsymbol{1}}\right)$ or proximal $\left(\boldsymbol{A}_{\mathbf{2}}\right)$ dendrites. Minimal responses to distal stimulation (top traces) show paired-pulse depression, whereas analogous responses to proximal stimulation show paired-pulse facilitation. Increasing the stimulus intensity to recruit additional axons (bottom traces) did not change the type of paired-pulse modulation at either synapse. Both distal and proximal EPCSs were blocked by the non-NMDA glutamate receptor antagonist NBQX (10 $\mu \mathrm{m}$; gray traces). Images above traces show relationship between Alexa 594-filled stimulating pipette and the recorded neuron. Scale bars: $A_{1}, 10 \mu \mathrm{m} ; A_{2}, 5 \mu \mathrm{m}$. The stimulating electrode tip is indicated by a tan asterisk. $\boldsymbol{B}_{1}$, Summary graphs showing PPR calculated by mean EPSC amplitudes for 12 minimal stimulation experiments (left) and 17 supraminimal stimulation experiments (right). Paired-pulse ratios were significantly different between proximal and distal stimulus sites at both stimulus intensity ranges $\left({ }^{* *} p<0.01\right)$. Paired-pulse ratios for individual experiments are shown by open circles. Red filled circles in the supraminimal graph represent results from a single granule cell that was stimulated at both proximal and distal dendritic sites. $\boldsymbol{B}_{2}$, Plot of the paired-pulse ratio versus distance between the cell body and the stimulating electrode. The inset shows significant difference $(p<0.01)$ in PPRs between proximal and distal distance-controlled 2PGMS experiments. C, Paired-pulse depression at distal synapses was associated with a statistically significant increase in failure rate (left) at minimal stimulus intensities, whereas paired-pulse facilitation at proximal synapses resulted in a decrease in failure rate (right; ${ }^{*} p<0.05$.) $\boldsymbol{D}$, Plot of PPR calculated by mean EPSC amplitude versus the PPR calculated as the ratio of quantal contents $(\mathrm{m})$ obtained by analyzing failure rates. Both proximal (purple dots) and distal minimal stimulation results (gold dots) fall near the dashed line representing equal PPR ratios. between proximal and distal 2PGMS responses reflected multiple types of excitatory synapses with different functional properties. As shown in Figure $3 A_{1}$, responses to distal stimulation near dendritic segments in the EPL (using both two-photon guided minimal and supraminimal stimulation methods) showed paired-pulse depression (mean distal 2PGMS PPR, $0.74 \pm 0.09 ; n=7$; mean supraminimal PPR, $0.67 \pm 0.07 ; n=7)$. In contrast, proximal stimulation near dendritic segments in the GCL showed paired-pulse facilitation (Fig. $3 A_{2}$ ) (mean proximal minimal stimulation PPR, $1.74 \pm 0.22 ; n=5$; mean supraminimal stimulation PPR, $1.50 \pm 0.13 ; n=10$ ). The proximal/distal difference in pairedpulse ratio was statistically significant for both minimal and supraminimal stimulation $(p<0.01)$ (Fig. $\left.3 B_{1}\right)$. We also noted similar mean paired-pulse ratios using both minimal and supraminimal stimulation in the same stimulus location, suggesting that the cellular mechanisms responsible for these forms of short-term plasticity are unlikely to reflect neurotransmitter spillover (Isaacson et al., 1993). We also verified that the differences we found in proximal and distal stimulation experiments did not reflect functionally distinct subpopulations of granule cells by demonstrating that paired stimulation in the EPL induced depressing responses, whereas stimulation in the GCL induced facilitating responses in the same granule cell (Fig. $3 B_{1}$, right, red circles).

We also considered the possibility that these differences in short-term plasticity reflect extremes along a continuum related to distance from the cell body. We tested for this possibility by comparing the short-term plasticity at a subset of synapses located at a constant distance from the soma. In half of these experiments (four of nine), we defined paired-pulse ratios using 2PGMS at sites in the EPL while we stimulated in the GCL in the other five experiments. Both EPL and GCL stimulation sites were located from $\sim 100 \mu \mathrm{m}$ from the cell body (mean distance, 99.4 $\mu \mathrm{m}$ for EPL stimulation and $103.1 \mu \mathrm{m}$ for GCL stimulation). (We used granule cells, the cell bodies of which were located deeper in the GCL for these proximal stimulation experiments.) As shown in Figure $3 B_{2}$, we observed the same difference in paired-pulse ratio between these distance-controlled GCL and EPL stimulation experiments (mean paired-pulse ratio for GCL stimulation, $1.64 \pm 0.22$ vs $0.69 \pm 0.13$ for EPL stimulation; significantly different; $p<0.01$ ) as shown above 
using our larger population of proximal and distal 2PGMS experiments. We also found no correlation with the distance between the stimulating electrode and the cell body and the paired-pulse ratio (Fig. $3 B_{2}$ ). These results suggest that this difference in shortterm plasticity relates more to the laminar position of the synaptic input (located in the EPL or GCL) than to electrotonic distance from the cell body.

We found a very high correlation between the form of shortterm plasticity and the stimulus position. In a survey of 43 granule cells tested with two-photon guided supraminimal paired stimulation, the vast majority $(95 \% ; 21$ of 22$)$ of the experiments with the stimulus electrode positioned near proximal apical dendrites in the GCL showed facilitating responses (PPR, >1.2). The remaining one proximal stimulation experiment showed PPR of $\sim 1$. In contrast, most $(86 \% ; 18$ of 21$)$ of the distal EPL stimulation experiments showed paired-pulse depression (PPR, $<0.8$ ). Of the remaining three distal stimulation experiments, two showed paired-pulse facilitation $(P P R,>1.2)$ and one showed PPR of $\sim 1$. Responses to both proximal and distal stimulation at $-70 \mathrm{mV}$ were blocked completely by the non-NMDA receptor antagonist NBQX $(10 \mu \mathrm{M} ; n=5$ proximal and three distal stimulation experiments) (Fig. $3 A$, gray traces), indicating that both stimulation sites activated purely glutamatergic postsynaptic responses. The different forms of short-term plasticity evident in these focal stimulation experiments suggest that proximal and distal stimuli activate different types of glutamatergic synapses onto granule cells.

Both forms of short-term plasticity appear to result from changes in presynaptic release properties. The paired-pulse depression observed with distal two-photon guided minimal stimulation was associated with a statistically significant increase in the failure rate (from $0.49 \pm 0.04$ on stim $_{1}$ to $0.62 \pm 0.04$ on $\operatorname{stim}_{2} ; p<0.05 ; n=7$ ) (Fig. $3 C$, left) without a change in the average amplitude of successes (mean potency ratio, $R_{2} / R_{1}$, $0.99 \pm 0.05 ; n=7$ ). Similarly, the facilitation of responses with proximal two-photon guided minimal stimulation was associated with a significant decrease in the failure rate (from $0.59 \pm$ 0.10 on $\operatorname{stim}_{1}$ to $0.42 \pm 0.09$ on $\operatorname{stim}_{2} ; p<0.05 ; n=5$ ) (Fig. $3 C$, right), also without a change in potency (potency ratio, $1.03 \pm$ $0.07 ; n=5$ ). For both proximal and distal minimal stimulation, the PPR calculated by mean response amplitudes was strongly correlated with the PPR calculated as the ratio of quantal contents estimated by failure rates $(r=0.97)$ (Fig. 3D), consistent with presynaptic expression mechanisms for both forms of short-term plasticity.

Proximal and distal glutamatergic synapses also differed in their degree of depression during high-frequency stimulus trains. As shown in Figure $4 A$, responses to distal stimulation in the EPL were silenced by the fourth stimuli in a $50 \mathrm{~Hz}$ stimulus train. Responses to proximal stimulation initially showed facilitation, followed by steady-state depression and persisted after each stimuli in the train. Figure $4 B$ shows a summary of four proximal and four distal experiments using similar stimulus trains. Proximal synapses showed significantly less steady-state depression at the end of these stimulus trains than did distal synapses $(40.0 \pm 3.8$ vs $19.9 \pm 2.3 \%$ of initial response; $p<0.01$ ) (Fig. $4 B$, inset). We also tested whether proximal and distal synapses showed differences in the frequency dependence of their paired-pulse modulation. As shown in Figure 4C, paired-pulse modulation of both proximal and distal synapses was maximal with interstimulus intervals (ISIs) $<200 \mathrm{~ms}$; depression was maximal with very short $(<20$ $\mathrm{ms}$ ) ISIs, whereas facilitation was maximal with slightly longer
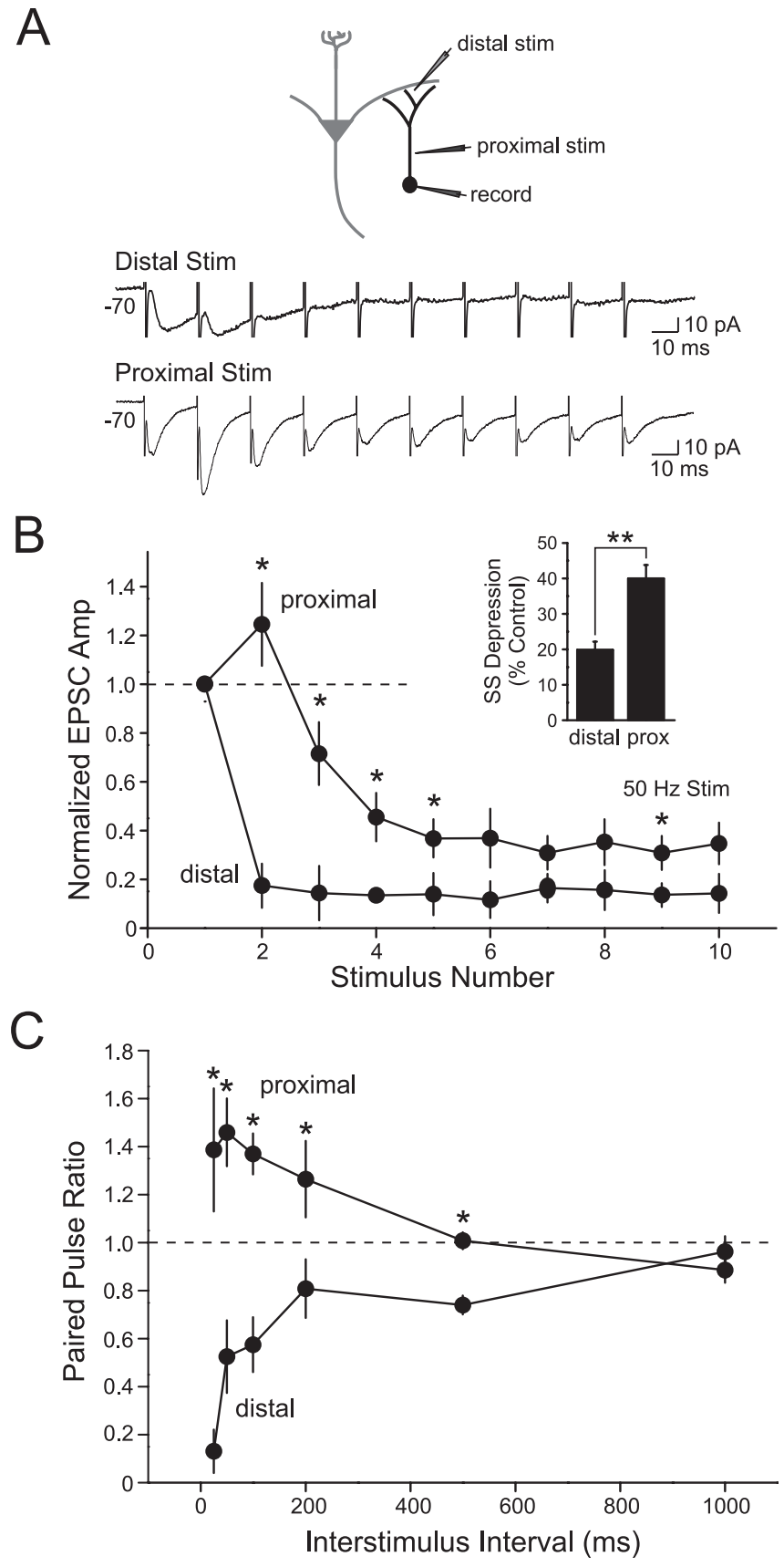

Figure 4. Frequency-dependent modulation at distal and proximal excitatory synapses. $\boldsymbol{A}$, Granule cell responses to a $50 \mathrm{~Hz}$ supraminimal distal (top) and proximal (bottom) stimulus train. Note the rapid silencing of the distal response by the fourth stimulus. Proximal synapses initially facilitate then show steady-state depression. $\boldsymbol{B}$, Summary of eight experiments using two-photon guided $50 \mathrm{~Hz}$ stimulus trains ( 4 proximal and 4 distal) $\left({ }^{*} p<0.05\right)$. The inset shows mean steady-state depression in the last three responses of the train for proximal and distal stimulation normalized to the initial response amplitude $\left({ }^{* *} p<0.01\right)$. C, Plot of the pairedpulse ratio, calculated from the mean supraminimal response amplitude, versus interstimulus interval for four proximal two-photon guided stimulation (stim) experiments and four distal experiments $\left({ }^{*} p<0.05\right)$.

ISIs (20-50 ms). Both forms of paired-pulse modulation were abolished with ISIs of $1 \mathrm{~s}$ or greater.

The results presented thus far suggest that proximal and distal excitatory synapses onto granule cells are functionally distinct, because they have different kinetics, different forms short-term plasticity, and different degrees of steady-state depression. We next examined responses to proximal and distal stimulation at 
different membrane potentials to determine whether there were also differences in the NMDA receptor components of the EPSCs. Blockade of NMDA receptors with D-APV $(50 \mu \mathrm{M})$ had little effect on the response to either proximal or distal focal stimulation when granule cells were held at hyperpolarized membrane potentials. APV blocked only a small fraction of $-70 \mathrm{mV}$ EPSC current integral in both responses to proximal $(9.41 \pm 2.2 \%$ of control; $n=4)$ and distal ( $12.2 \pm 3.5 \%$ of control; $n=4)$ supraminimal stimulation, suggesting that the difference in kinetics between these EPSCs was not caused by a differential contribution of NMDA receptor (NMDAR) activation at $-70 \mathrm{mV}$. When tested at depolarized potentials, both proximal and distal 2Pguided AMPA receptor (AMPAR)-mediated responses recorded rectified strongly (ratio of $-70 /+50 \mathrm{mV}$ proximal EPSC amplitude in APV, $3.85 \pm 0.64 ; n=4$; distal, $3.25 \pm 0.36 ; n=4$; using these holding potentials, nonrectifying synaptic responses would yield a ratio of 1.4).

\section{What is the source of the proximal excitatory input to granule cells?}

Previous work suggested two potential sources of excitatory, glutamatergic inputs to the proximal dendrites of granule cells: local collaterals of mitral cell axons and centrifugal feedback projections from cortical regions. We used two-photon imaging and a combined olfactory bulb/piriform cortex slice preparation to determine whether centrifugal projections from piriform cortex could generate proximal 2PGMS-like postsynaptic responses in granule cells. We first asked whether these slices maintained any of the feedback projections from piriform cortex that normally innervate the granule cell layer in the olfactory bulb (de Olmos et al., 1978; Haberly and Price, 1978; Shipley and Adamek, 1984). We tested this by making focal DiI injections in APC in fixed slices ( $3 \mathrm{~mm} ; 500 \mathrm{~ms}$ pressure pulse duration; $2 \mathrm{psi} ; n=8$ slices). After waiting $14 \mathrm{~d}$ for DiI to diffuse throughout the axonal arborizations, we were able to visualize abundant labeled axons, many with en passant terminals, in the granule cell layer in most DiI-injected slices (seven of eight) (Fig. 5A, inset). None of the eight slices with DiI injections in the APC had labeled mitral cells. In contrast, all five control experiments with DiI injections in the lateral olfactory tract (LOT) showed abundant labeled mitral cells (data not shown), suggesting that the APC injection protocol selectively labeled piriform cortical neurons, including a subpopulation of pyramidal cells that project to the olfactory bulb granule cell layer.

After verifying that the cortical feedback pathway was preserved in these horizontal slices, we tested whether focal stimulation in layers 2-3 of anterior piriform cortex activated EPSCs on granule cells. We recorded EPCSs in granule cells in approximately one-third of the combined OB/APC slices tested. Figure $5 B$ illustrates EPSCs evoked by minimal stimulation in layers $2-3$ of anterior piriform cortex. Cortical stimulation evoked purely fast-rising EPSCs in granule cells (mean rise time, $1.10 \pm 0.03 \mathrm{~ms}$; $n=6$ cells) that resembled the EPSCs evoked by proximal 2PGMS. Cortical EPSCs also facilitated with paired-pulse stimulation (mean PPR, $1.62 \pm 0.21$ ) (Fig. 5C). In contrast, minimal stimulation in the superficial layer of APC, activating axons in the lateral olfactory tract, evoked purely slow-rising EPSCs (mean rise time, $3.73 \pm 0.15 \mathrm{~ms} ; n=5$ ) (Fig. $5 B$ ) that depressed with paired-pulse stimulation (mean PPR, $0.55 \pm 0.14$ ) and resembled distal 2PGMS responses. Both the changes in EPSC rise time (Fig. $5 D$ ) and paired-pulse ratio (Fig. $5 E$ ) were significantly different between the APC and LOT stimulation sites. The distallike minimal responses evoked by LOT stimulation in the com-
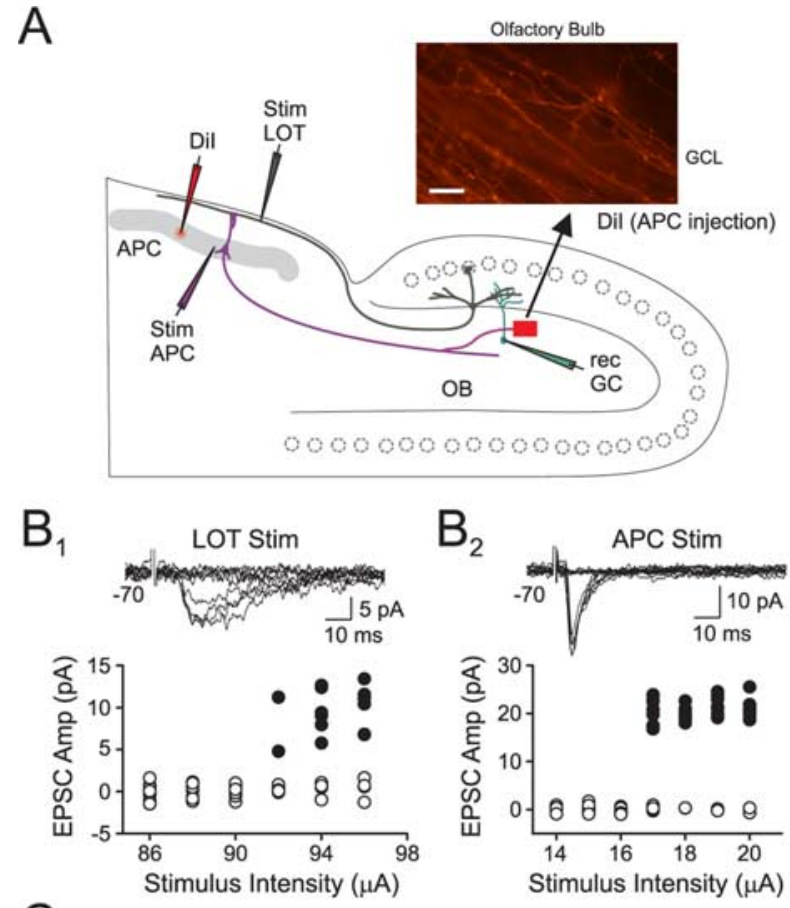

C
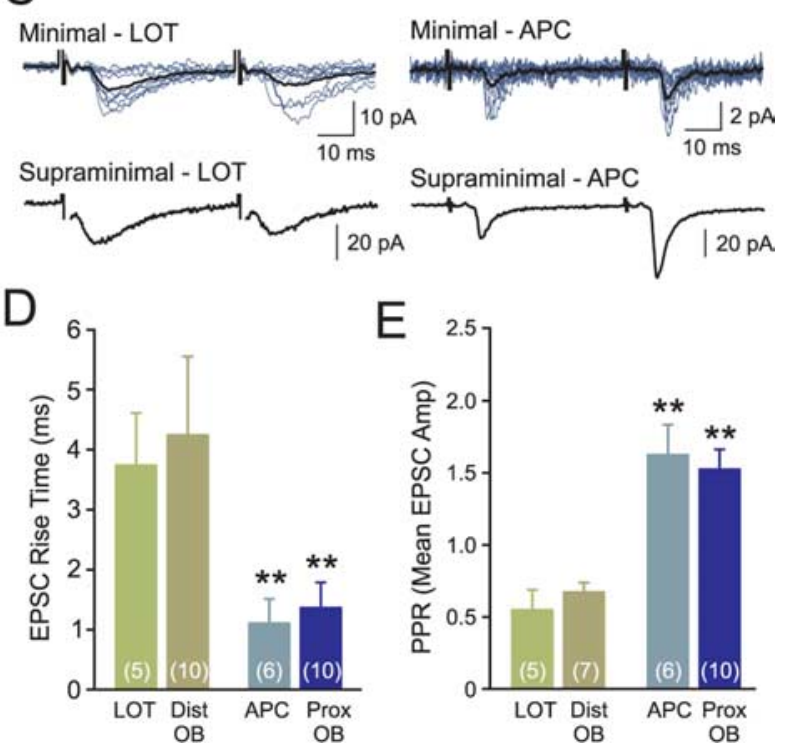

Figure 5. Cortical feedback projections generate facilitating, fast-rising EPSCs in granule cells. $\boldsymbol{A}$, Diagram of the combined olfactory bulb-anterior piriform cortex slice preparation. Mitral cell axon collaterals and cortical feedback projections were independently activated by stimulating the LOT or the deep pyramidal cell layer of the APC, respectively. Focal Dil injections in the APC confirmed that the combined OB-APC brain slice contained cortical axons that innervated the olfactory bulb. The inset shows Dil-labeled axons with en passant boutons in the GCL. $\boldsymbol{B}$, Granule cell responses to minimal LOT stimulation (stim) in the APC $\left(\boldsymbol{B}_{\boldsymbol{1}}\right)$ and focal APC stimulation $\left(\boldsymbol{B}_{2}\right)$. Antidromic mitral cell activation (LOT stimulation) evoked slow-rising EPSCS that resembled the distal responses shown in Figure $1 D$, whereas APC stimulation evoked fast-rising EPSCS that resembled proximal responses. C, Both minimal and supraminimal LOT stimulation evoked EPSCs that depressed (left), whereas EPSCs evoked by APC stimulation facilitated (right). D, Summary plot of mean EPSC rise time for minimal LOT $(n=5)$ and APC $(n=6)$ stimulation experiments. Corresponding results from two-photon guided focal stimulation of distal (gold shading) and proximal (purple shading) also are replotted from Figure $2 C$. APC-evoked EPSCs had significantly faster rise times than both LOT- and distal OB-evoked minimal EPSCs ( ${ }^{* *} p<0.01$; one-way ANOVA). E, Summary graph of paired-pulse ratio, calculated from mean EPSC amplitude, for five LOT and six APC stimulation experiments. Corresponding results from distal and proximal $O B$ stimulation are replotted from Figure $3 B_{1}$ for comparison. The PPR of APC-evoked EPSCs was significantly greater than either LOT-or distal OB-evoked EPSCs ( ${ }^{* *} p<0.01$; one-way ANOVA). 
bined APC/OB slices did not have the increased latency jitter observed in responses to 2PGMS in the EPL (Fig. $1 D_{1}$ ) (APC latency jitter, $0.74 \pm 0.26 \mathrm{~ms}$; LOT latency jitter, $0.78 \pm 0.17 \mathrm{~ms}$ ). This difference may reflect differences in the reliability of spike initiation by weak focal axonal (in the LOT) versus dendritic (in EPL) stimulation. Together, these results suggest that at least in part of the proximal excitatory input to granule cells arise from feedback cortical projections.

We then asked whether the cortical feedback projections to granule cells could regulate dendrodendritic inhibition. As shown in Figure $6 B$, mitral cell DDI responses evoked by a brief depolarizing step in Mg-free ACSF are blocked by both bath application of D-APV (Fig. $6 B_{1}$ ) and by extracellular $\mathrm{Mg}\left(1.2 \mathrm{~mm}\right.$ ) (Fig. $6 B_{2}$ ), reflecting the critical role NMDARs play in triggering dendrodendritic inhibition shown previously (Isaacson and Strowbridge, 1998; Schoppa et al., 1998). In physiological $\mathrm{Mg}$ concentrations (1.2 $\mathrm{mM})$, depolarizing steps evoked a small inward current (Fig. 6C, left traces), presumably because of the autoreceptormediated current previously described on mitral cells (Isaacson, 1999; Friedman and Strowbridge, 2000). However, the same depolarizing steps evoked robust dendrodendritic inhibition when paired with an APC tetanus $(n=5)$. At this stimulus intensity, the APC tetanus did not evoke any synaptic responses in the mitral cell by presented by itself $(n=5)$. The outward currents evoked by the combined DDI/APC stimulus were blocked by the $\mathrm{GABA}_{\mathrm{A}}$ receptor antagonist gabazine (Fig. $6 C$, right traces) $(10 \mu \mathrm{M}$; three of three experiments), demonstrating that they reflected inhibitory synaptic input. The results from this set of experiments is summarized in Figure $6 D$ and demonstrate that feedback projections from APC can gate dendrodendritic inhibition in physiological concentrations of $\mathrm{Mg}$.

\section{Do granule cells have silent synapses?}

Not all glutamatergic synapses in the CNS contain both functional AMPA and NMDA receptors (Isaac et al., 1995, 1997; Liao et al., 1995). This phenomenon, typically referred to as "silent synapses," reflects different distributions of glutamate receptor subunits at dendritic sites in the vicinity of postsynaptic active zones (Malinow and Malenka, 2002; Isaac, 2003). Differences in glutamate receptor composition can have dramatic consequences on the nature of the postsynaptic response; AMPAR silent synapses, an extreme example, generate no postsynaptic response at hyperpolarized membrane potentials. Also, several forms of long-term plasticity appear to be mediated by movement of "spare" receptors into the postsynaptic zone after synaptic activity where they then can contribute to the postsynaptic response (Bredt and Nicoll, 2003). One potential explanation for the inability of non-NMDA receptors to drive robust dendrodendritic inhibition is the absence of functional AMPARs at distal granule cell synapses.

We used 2PGMS to investigate the receptor subunit composition in excitatory synapses on granule cells and to ask whether

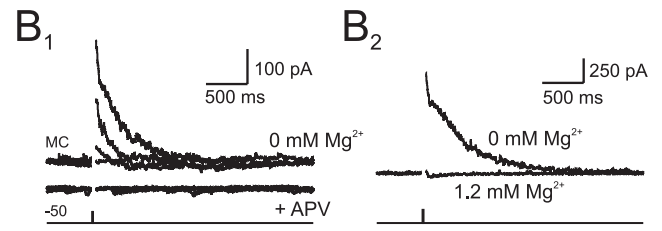

$\mathrm{D}$

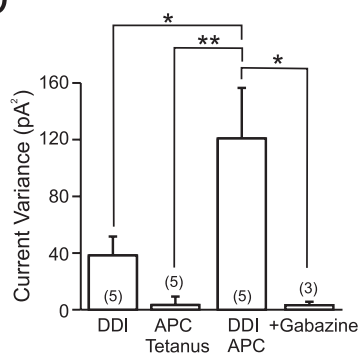

Figure 6. Cortical synaptic input gates dendrodendritic inhibition onto mitral cells. $\boldsymbol{A}$, Diagram of experiment. $\boldsymbol{B}_{\boldsymbol{1}}$, Dendroden列 The $G A B A_{A}$ receptor antagonist gabazine $(10 \mu \mathrm{m})$ blocked the dendrodendritic inhibition associated variance increase $\left({ }^{*} p<0.05\right.$; ${ }^{* *} p<0.01$ ). All experiments in $C$ and $\boldsymbol{D}$ were conducted with normal ACSF (containing $1.2 \mathrm{~mm} \mathrm{Mg}$ ).

granule cells have AMPAR or NMDAR silent synapses. One approach to test for silent synapses, shown in Figure $7 A$, is based on comparing minimal stimulation failure rates at -70 and +50 $\mathrm{mV}$. The plots in Figure $7 A_{1-2}$ illustrate the most common results we observed: dual-component EPSCs interspersed with failures. Given the strong rectification of proximal and distal AMPARmediated synaptic currents we recorded in granule cells (see above), we expected that most successes recorded at $+50 \mathrm{mV}$ reflected currents through NMDAR receptors. We confirmed this in two granule cell experiments in which we found that bath application of $50 \mu \mathrm{M}$ D-APV abolished all successes recorded at $+50 \mathrm{mV}$ using $2 \mathrm{PGMS}$. The same data sets shown as time plots in Figure $7 A$ are replotted in Figure $7 B$ as response amplitude histograms. In these two experiments, in the proportion of responses categorized as failures was approximately the same when the granule cell was held at -70 and at $+50 \mathrm{mV}$, suggesting that these responses included both AMPAR and NMDAR-mediated components (i.e., dual-component). Approximately three quarters of our 2PGMS experiments on granule cells fit this pattern (69\% with proximal 2PGMS and 70\% with distal 2PGMS) and were classified as dual-component EPSCs. None of the granule cell experiments categorized as dual-component had failure rates $>90 \%$ at either -70 or $+50 \mathrm{mV}$ holding potentials or statistically significant changes in the failure rate at the two potentials $\left(\chi^{2}\right.$ test; significance threshold of $p<0.01$ ).

A minority of granule cell synapses activated using 2PGMS appeared to be NMDAR silent. An example of this type of synapse is shown in Figure $7 A_{3}$. In this experiment, proximal 2PGMS evoked clear successes at $-70 \mathrm{mV}$ but almost no successes when the granule cell was held at $+50 \mathrm{mV}$. We confirmed that this cell was not damaged by the transient depolarization to $+50 \mathrm{mV}$ by verifying that successes still occurred when the cell was returned to $-70 \mathrm{mV}$. Figure $7 B_{3}$ shows the amplitude distributions calcu- 
$A_{1}$
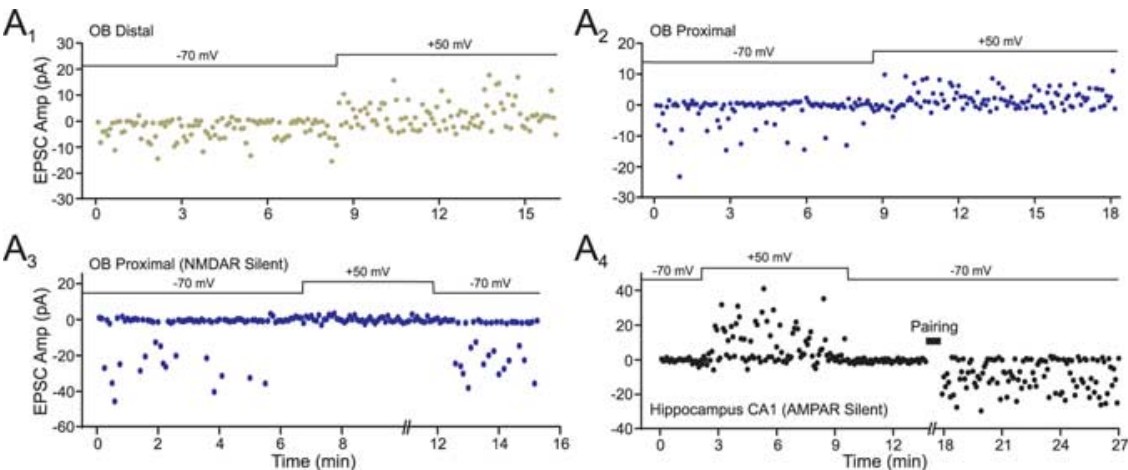

$\mathrm{A}_{4}$

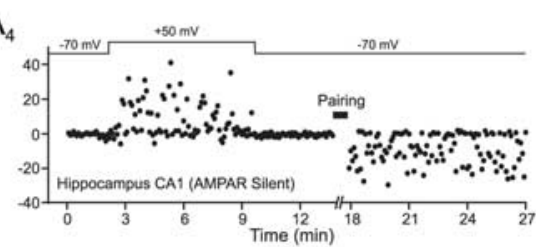

$\mathrm{B}_{1}$

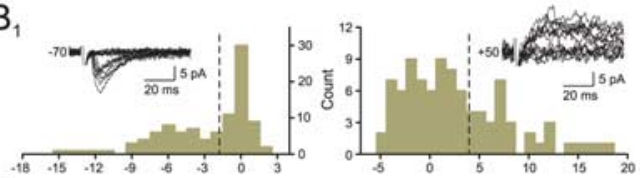

$\mathrm{B}_{2}$

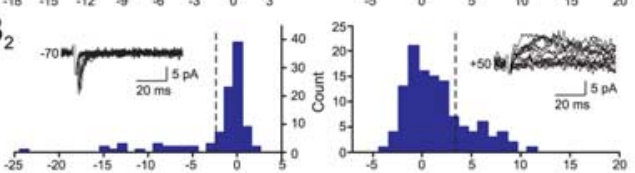

$\mathrm{B}_{3}$

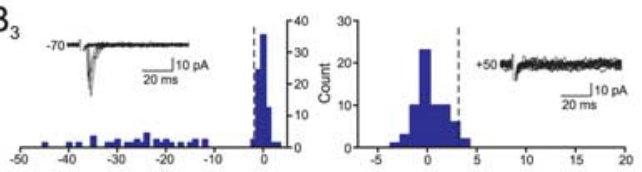

$\mathrm{B}_{4}$
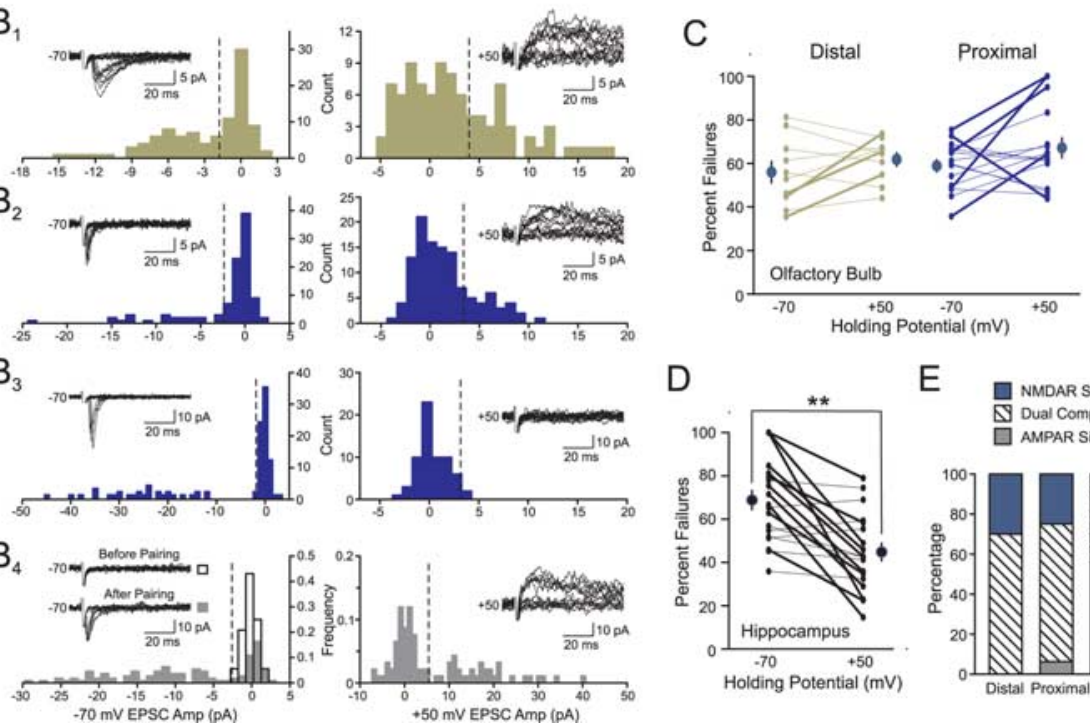

Figure 7. Tests for AMPAR and NMDAR silent excitatory synapses on granule cells. $\boldsymbol{A}$, Plots of response amplitude to twophoton guided minimal stimulation at $0.2 \mathrm{~Hz}$ in the $\operatorname{EPL}\left(A_{1}\right)$, the GCL $\left(A_{2}-A_{3}\right)$, and stratum radiatum stimulation of a hippocampal CA1 pyramidal cell $\left(\boldsymbol{A}_{4}\right)$. Membrane potentials are indicated above each plot. Experiments in $\boldsymbol{A}_{1}$ and $\boldsymbol{A}_{2}$ illustrate examples of dual (NMDA and non-NMDA receptor) component minimal stimulation responses. $A_{3}$ illustrates an example of NMDA receptor silent granule cell response. $A_{4}$ illustrates an example of an AMPA receptor silent response in a CA1 pyramidal cell that was converted into a dual component response by pairing 50 minimal stimuli with intracellular depolarization to $0 \mathrm{mV}$. $\boldsymbol{B}$, Amplitude histograms generated from the responses plotted in $\boldsymbol{A}$. Separate histograms are shown for responses at -70 and $+50 \mathrm{mV} ; \boldsymbol{B}_{4}$ shows the change in the $-70 \mathrm{mV}$ response amplitude distribution before (open bars) and after (shaded bars) pairing. The vertical dashed line represents $2 \times S D$ of the noise distribution. Example traces are shown above each plot. $C, D$, Summary plots of the results from experiments using proximal ( $\boldsymbol{C}$, right; $n=16$ cells) and distal ( $\boldsymbol{C}$, left; $n=10$ cells) two-photon guided minimal stimulation of granule cells and stratum radiatum stimulation of CA1 pyramidal cells $(\boldsymbol{D} ; n=19$ cells). Each summary plot shows the response failure rate at -70 and $+50 \mathrm{mV}$ (inside dots connected by lines) and the overall failure rate for the each group of experiments at -70 and $+50 \mathrm{mV}$ (outside dots with error bars). Only the group of experiments using CA1 pyramidal cells showed a statistically significant difference in mean failure rate at -70 and $+50 \mathrm{mV}\left({ }^{* *} p<0.01\right.$; paired $t$ test). Analysis of the failure rate in each individual experiment showed statistically significant differences between -70 and $+50 \mathrm{mV}$ in 5 of 16 proximal and 3 of 10 distal granule cell minimal stimulation experiments and 11 of 19 CA1 pyramidal minimal stimulation experiments (thick lines; $\chi^{2}$ test; $p<0.01$; three experiments with $100 \%$ failures at $-70 \mathrm{mV}$ included in significant difference category). $\boldsymbol{E}$, Summary plot showing the proportion of experiments classified as NMDAR silent (blue; statistically higher failure rate at +50 than $-70 \mathrm{mV} ; p<0.01$ ), AMPAR silent (gray; statistically greater failure rate at -70 than $+50 \mathrm{mV} ; p<0.01$ ), and dual component (hashed; no statistically significant difference in failure rates at -70 and $+50 \mathrm{mV} ; p>0.01$ ) for the three stimulation sites.

lated from this experiment and demonstrate clearly separable successes and failures at $-70 \mathrm{mV}$ but not at $+50 \mathrm{mV}$, suggesting that this proximal synapse contained AMPA receptors but no functional NMDA receptors. Approximately one-fourth of the granule cell 2PGMS experiments resembled this example (30\% proximal 2 PGMS and 25\% distal 2PGMS) and were categorized as NMDAR silent. All of the distal $(n=3)$ and one of the proximal synaptic responses categorized as NMDAR silent were not completely "silent" at $+50 \mathrm{mV}$ but rather had intermediate failures rates at $+50 \mathrm{mV}$, which were decreased significantly at -70

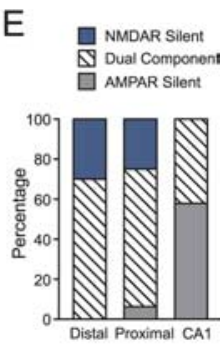

$\mathrm{mV}$. The remainder of the proximal synapses categorized as NMDAR silent $(n=$ 3) had failure rates $>90 \%$ at $+50 \mathrm{mV}$.

We found a very small incidence of AMPAR silent synapses onto granule cells (0 of 10 for distal 2PGMS and 1 of 16 for proximal 2PGMS), a synaptic phenotype that is very common in the hippocampus (Isaac et al., 1995; Liao et al., 1995; Isaac, 2003). We replicated the results from these hippocampal studies by recording responses to minimal stimulation in CA1 pyramidal cells under the same conditions as in our olfactory bulb slice experiments. We found evidence for AMPAR silent synapses in approximately half $(58 \% ; 11$ of 19) of our hippocampal experiments. Figure $7 A_{4}$ shows an example of an AMPAR silent hippocampal synapse with a very high failure rate at $-70 \mathrm{mV}$ but frequent successes at $+50 \mathrm{mV}$. Only one 2PGMS olfactory bulb experiment (of 26 experiments) resembled the prepairing conditions shown in Figure $7 B_{4}$, suggesting that the incidence of AMPAR silent synapses is very low in granule cells.

The results from all of the olfactory bulb and hippocampal silent synapse experiments are plotted in Figure 7, $C$ and $D$. Although there was a statistically significant change in the mean failure rate in our set of hippocampal experiments (from $68.8 \pm 4.4 \%$ at $-70 \mathrm{mV}$ to $44.8 \pm 4.1 \%$ at $+50 \mathrm{mV} ; n=19 ; p<0.01$; paired $t$ test), there was no difference in the mean population failure rate in either set of proximal or distal olfactory bulb 2PGMS experiments $(p>0.05)$. As discussed above, five proximal and three distal olfactory bulb experiments and 11 of 19 hippocampal experiments showed statistically significant changes in the failure rate when analyzed individually ( $\chi^{2}$ test; $p<0.01$ ) (Fig. $7 C, D$, thick lines). The overall proportion of AMPAR silent, NMDAR silent, and dual-component EPSCs that we recorded is shown in Figure 7E.

We performed several additional experiments to test for AMPAR silent synapses on granule cells. In nine experiments, we initially searched for minimal responses in granule cells held at $-70 \mathrm{mV}$ and then gradually reduced the stimulus intensity until we recorded no successes (all failures). We tested for successes at $+50 \mathrm{mV}$ at this stimulus intensity but found no evidence for AMPAR silent responses. We also verified that pairing synaptic stimulation with intracellular depolarization (shown by horizontal bar in Fig. $7 A_{4}$ ) could convert an AMPAR silent hippocampal synapse into a dual-component synapse. Pairing successfully revealed AMPAR-mediated EPSCs in three of five hippocampal experiments. As shown in the hippocampal amplitude histograms in Figure $7 B_{4}$, before pairing, there were no responses at $-70 \mathrm{mV}$ with amplitudes greater than $-3 \mathrm{pA}$, whereas 
after pairing, most of the response amplitudes were between -5 and $-30 \mathrm{pA}$. A similar pairing protocol was not successful in revealing an AMPAR-mediated component in the one AMPAR silent granule cell synapse we found (data not shown). We also tested whether pairing protocols altered the $-70 /+50 \mathrm{mV}$ failure ratio in seven granule cell $2 \mathrm{PGMS}$ experiments. The same pairing protocol that was effective with hippocampal synapses failed to modulate the $-70 /+50 \mathrm{mV}$ failure rate ratio in all of these olfactory bulb experiments, suggesting that long-term plasticity may be mediated by different cellular mechanisms in these two brain regions.

\section{Discussion}

In this study, we investigated the functional properties of excitatory inputs in the olfactory bulb using a novel technique, twophoton guided minimal stimulation, to evoke transmitter release at defined positions along granule cell dendritic trees. We made three principle conclusions in this study. First, distal dendrodendritic and proximal axodendritic excitatory inputs form functionally distinct synapses. Dendrodendritic inputs from mitral cells have slow kinetics and show paired-pulse depression, whereas proximal axonal inputs have fast kinetics and facilitate. Second, we found that centrifugal inputs originating in piriform cortex generate facilitating proximal axodendritic synapses onto granule cells and can gate dendrodendritic inhibition onto mitral cells. Finally, unlike other brain regions such as the hippocampus (Isaac et al., 1995; Liao et al., 1995) and neocortex (Isaac et al., 1997; Feldman et al., 1998; Rumpel et al., 2005), both distal and proximal granule cell synapses generally are not AMPAR silent but surprisingly can be NMDAR silent.

Most previous studies using minimal stimulation to define the functional properties of specific types of synapses took advantage of anatomically defined fiber tracts to trigger transmitter release from a homogeneous population of synapses. Because the olfactory bulb lacks anatomically defined, homogenous fiber pathways, it is difficult to selectively activate different types of axon terminals in this brain region using conventional extracellular stimulation methods. By using two-photon imaging to position an extracellular simulating electrode near a specific dendritic segment, we were able to activate relatively homogenous populations of presynaptic processes, judging from the functional properties of the resulting postsynaptic responses. Previous studies have used two-photon imaging to position stimulating electrodes (Skeberdis et al., 2006) and to record quantal-like postsynaptic Ca transients (Oertner et al., 2002) in response to relatively large (supraminimal) stimuli. In our study, we combined two-photon imaging with minimal stimulation methods to define, for the first time, the differences at the single-synapse level (e.g., failure rates) between proximal and distal inputs to granule cells.

\section{Multiple pathways activate granule cells}

We found that the large degree of variability among evoked EPSCs in granule cells is not solely a result of different degrees of electrotonic filtering but rather reflects multiple types of functionally distinct glutamatergic inputs. We based this conclusion on the large differences in EPSC kinetics, the different forms of short-term plasticity, and the different degrees of steady-state depression we recorded following proximal versus distal focal stimuli. Although differences in EPSC kinetics may be partially explained by electrotonic filtering (Jack et al., 1983; Spruston et al., 1994), electrotonic effects cannot explain differences in shortterm plasticity and steady-state depression. These results strongly suggest that granule cells receive multiple types of excitatory inputs that have different functional properties.

Our results showing EPSCs with different kinetics evoked at proximal and distal synapses are consistent with a previous report of spontaneous fast- and slow-rising EPSCs in granule cells (Carleton et al., 2003). One previous study (Dietz and Murthy, 2005) investigated short-term plasticity at glutamatergic synapses in the olfactory bulb and found evidence for two classes of granule cells: one that received excitatory inputs that showed paired-pulse depression and another type that received facilitating inputs. Although we also found evidence for two classes of excitatory synapses, we found no evidence for separate subpopulations of granule cells that receive facilitating and depressing inputs. One explanation for this discrepancy is the different stimulating methods used in these studies. The 2PGMS method we used enabled us to selectively activate presynaptic processes relatively close to synaptic terminals on specific postsynaptic neurons. In contrast, extracellular stimulation at sites relatively distant from the postsynaptic dendrite might activate a combination of distal and proximal inputs, depending on the location of the stimulating electrode and the stimulus intensity. The relatively homogenous responses we observed after positioning stimulating pipettes near specific dendritic segments argues strongly that different functional properties we observe are correlated with distal dendrodendritic and proximal axodendritic synapses and not with subpopulations of granule cells.

Using combined olfactory bulb-piriform cortex slices, we found that proximal facilitating inputs onto granule cells arise at least in part from cortical feedback inputs. We showed that anterior piriform cortical neurons send numerous projections that ramify in the granule cell layers, in agreement with previous studies on the distribution of inputs from piriform cortex in the olfactory bulb (de Olmos et al., 1978; Haberly and Price, 1978; Shipley and Adamek, 1984) and classic work demonstrating that stimulation of deep piriform cortical layers excites olfactory bulb granule cells (Nakashima et al., 1978). Stimulating the anterior piriform cortex evoked fast facilitating EPSCs in granule cells that were indistinguishable from proximal synaptic inputs activated by 2 PGMS. Antidromically activating mitral cells by LOT stimulation evoked slowly rising EPSCs that depressed and were similar to EPSCs evoked by distal 2PGMS. Previous studies suggest that feedback inputs from the piriform cortex are extensive and may exceed the density of local excitatory input onto granule cells (Haberly, 2001). The same extensive feedback projection from anterior piriform cortex to granule cells may also mediate the large, long-latency negative field potential recorded in the isolated whole-brain preparation (Uva et al., 2006).

\section{Implications for long-term plasticity at dendrodendritic synapses}

The high concentration of NMDA receptors at granule cell spines (Sassoe-Pognetto and Ottersen, 2000) suggests that long-term potentiation of dendrodendritic transmission may be an important mechanism for synaptic plasticity in the olfactory bulb. In many brain regions, including the hippocampus (Isaac et al., 1995, 1996; Liao et al., 1995), cerebral cortex (Isaac et al., 1997; Feldman et al., 1999), and amygdala (Rumpel et al., 2005), longterm potentiation of synaptic transmission occurs through the insertion of AMPA receptors into AMPAR-silent spines. Our results suggest that long-term changes in synaptic efficacy at dendrodendritic synapses, if they exist, probably do not occur through classical long-term potentiation, because we only rarely observed AMPAR silent (rather than NMDAR silent) synapses on 
granule cells. Instead, plasticity at dendrodendritic synapses may occur through presynaptic changes in release probability or through intrinsic changes in granule or mitral cell excitability. The presence of NMDAR silent synapses onto granule cells also raises the intriguing possibility that plasticity in the olfactory bulb also may be mediated by activity-dependent insertion of NMDA receptors in dendrodendritic synapses. This mechanism may be especially relevant during development, because granule cells continue to be produced through adulthood in the subventricular zone and migrate into the olfactory bulb to be incorporated into existing olfactory bulb circuits (Lois and Alvarez-Buylla, 1994; Alvarez-Buylla and Garcia-Verdugo, 2002; Petreanu and Alvarez-Buylla, 2002; Carleton et al., 2003; Lledo et al., 2006). These adult-born granule cells initially express predominately AMPA receptors and later incorporate NMDA receptors (Carleton et al., 2003; Lledo et al., 2006), implying that even in adulthood, a subpopulation of granule cells may have NMDAR silent synapses.

\section{Functional significance of multiple excitatory inputs onto granule cells}

Reciprocal dendrodendritic synapses between mitral and granule cells provide the dominant source of both recurrent and lateral inhibition onto mitral cells (Rall et al., 1966; Shepherd and Greer, 1998). However, most studies of these microcircuits found the inhibitory output from granule cells was tonically attenuated by extracellular Mg ions that prevented permeation through NMDA receptors (Isaacson and Strowbridge, 1998; Schoppa et al., 1998; Chen et al., 2000). Our findings suggest that the NMDAR dependence of DDI is not attributable to the absence of AMPARs in dendrodendritic synapses but instead may reflect aspects of NMDAR-mediated responses that facilitate GABA release from granule cells [e.g., presynaptic Ca entry through NMDARs (Halabisky et al., 2000) or long-duration NMDAR EPSCs that outlast transient K currents (Schoppa and Westbrook, 1999)].

Our results suggest that cortical feedback projections can reverse the Mg blockade of NMDA receptors at distal dendrodendritic synapses on granule cells and can gate dendrodendritic inhibition onto mitral cells. The DDI gating effect we show is consistent with a previous report (Halabisky and Strowbridge, 2003) showing feedback inhibition triggered by mitral cell spikes paired with tetanic stimulation in the granule cell layer. Our results also are consistent with a previous report of gated DDI driven by photolyzing caged $\mathrm{Ca}$ in mitral cells combined with near coincident gamma-frequency stimulation in the GCL (Chen et al., 2000). The present results suggest that pyramidal neurons in piriform cortex may be the source of the proximal gating signal in these previous studies. The strong facilitation we found in proximal synapses onto granule cells also provides an explanation of why high-frequency GCL tetani are required to gate dendrodendritic inhibition (Halabisky and Strowbridge, 2003). Our results suggest that $20-50 \mathrm{~Hz}$ oscillations that normally occurs in populations of piriform cortical cells (Freeman, 1978) may reflect an endogenous "gating" signal that enables dendrodendritic microcircuits in the olfactory bulb.

Finally, our work suggests that the olfactory bulb and piriform cortex function as a tightly integrated system with piriform cortex providing a critical feedback excitatory input to granule cells. The relative timing between dendodendritic excitation and highfrequency discharges of piriform cortical neurons may regulate much of the GABA-mediated inhibition in the olfactory bulb. One prediction from this model is that the degree of lateral inhibition in the olfactory bulb after sensory stimulation may be dynamically modulated by activity in the piriform cortex. This agrees with a study showing context-dependent modulation of mitral cell spiking in vivo that is likely controlled by efferent cortical feedback (Kay and Laurent, 1999). Another prediction of our model is that interventions that boost overall activity levels in piriform cortex (e.g., focal stimulation or pharmacological disinhibition) should potentiate lateral dendrodendritic inhibition in the olfactory bulb and increase the dissimilarity between activity patterns of evoked by different odorants. At the other extreme, very little local processing may occur in the olfactory bulb when piriform cortex activity is depressed after anesthesia (Destexhe et al., 2003; Orth et al., 2006). The depression of cortical feedback to the bulb may contribute to the coordinate increase in odorevoked mitral cell responsiveness and decrease in response sparseness observed in anesthetized mice in vivo (Rinberg et al., 2006).

\section{References}

Alvarez-Buylla A, Garcia-Verdugo JM (2002) Neurogenesis in adult subventricular zone. J Neurosci 22:629-634.

Bredt DS, Nicoll RA (2003) AMPA receptor trafficking at excitatory synapses. Neuron 40:361-379.

Cang J, Isaacson JS (2003) In vivo whole-cell recording of odor-evoked synaptic transmission in the rat olfactory bulb. J Neurosci 23:4108-4116.

Carleton A, Petreanu LT, Lansford R, Alvarez-Buylla A, Lledo PM (2003) Becoming a new neuron in the adult olfactory bulb. Nat Neurosci 6:507-518.

Chen WR, Xiong W, Shepherd GM (2000) Analysis of relations between NMDA receptors and GABA release at olfactory bulb reciprocal synapses. Neuron 25:625-633.

del Castillo J, Katz B (1954) Quantal components of the end-plate potential. J Physiol (Lond) 124:560-573.

de Olmos J, Hardy H, Heimer L (1978) The afferent connections of the main and the accessory olfactory bulb formations in the rat: an experimental HRP-study. J Comp Neurol 181:213-244.

Destexhe A, Rudolph M, Pare D (2003) The high-conductance state of neocortical neurons in vivo. Nat Rev Neurosci 4:739-751.

Dietz SB, Murthy VN (2005) Contrasting short-term plasticity at two sides of the mitral-granule reciprocal synapse in the mammalian olfactory bulb. J Physiol (Lond) 569:475-488.

Feldman DE, Nicoll RA, Malenka RC, Isaac JT (1998) Long-term depression at thalamocortical synapses in developing rat somatosensory cortex. Neuron 21:347-357.

Feldman DE, Nicoll RA, Malenka RC (1999) Synaptic plasticity at thalamocortical synapses in developing rat somatosensory cortex: LTP, LTD, and silent synapses. J Neurobiol 41:92-101.

Frazier CJ, Strowbridge BW, Papke RL (2003) Nicotinic receptors on local circuit neurons in dentate gyrus: a potential role in regulation of granule cell excitability. J Neurophysiol 89:3018-3028.

Freeman WJ (1978) Spatial properties of an EEG event in the olfactory bulb and cortex. Electroencephalogr Clin Neurophysiol 44:586-605.

Friedman D, Strowbridge BW (2000) Functional role of NMDA autoreceptors in olfactory mitral cells. J Neurophysiol 84:39-50.

Haberly LB (2001) Parallel-distributed processing in olfactory cortex: new insights from morphological and physiological analysis of neuronal circuitry. Chem Senses 26:551-576.

Haberly LB, Price JL (1978) Association and commissural fiber systems of the olfactory cortex of the rat. J Comp Neurol 178:711-740.

Halabisky B, Strowbridge BW (2003) Gamma-frequency excitatory input to granule cells facilitates dendrodendritic inhibition in the rat olfactory bulb. J Neurophysiol 90:644-654.

Halabisky B, Friedman D, Radojicic M, Strowbridge BW (2000) Calcium influx through NMDA receptors directly evokes GABA release in olfactory bulb granule cells. J Neurosci 20:5124-5134.

Hamilton KA, Kauer JS (1985) Intracellular potentials of salamander mitral/tufted neurons in response to odor stimulation. Brain Res 338:181-185.

Hamilton KA, Kauer JS (1989) Patterns of intracellular potentials in salamander mitral/tufted cells in response to odor stimulation. J Neurophysiol 62:609-625. 
Isaac JT (2003) Postsynaptic silent synapses: evidence and mechanisms. Neuropharmacology 45:450-460.

Isaac JT, Nicoll RA, Malenka RC (1995) Evidence for silent synapses: implications for the expression of LTP. Neuron 15:427-434.

Isaac JT, Hjelmstad GO, Nicoll RA, Malenka RC (1996) Long-term potentiation at single fiber inputs to hippocampal CA1 pyramidal cells. Proc Natl Acad Sci USA 93:8710-8715.

Isaac JT, Crair MC, Nicoll RA, Malenka RC (1997) Silent synapses during development of thalamocortical inputs. Neuron 18:269-280.

Isaacson JS (1999) Glutamate spillover mediates excitatory transmission in the rat olfactory bulb. Neuron 23:377-384.

Isaacson JS, Strowbridge BW (1998) Olfactory reciprocal synapses: dendritic signaling in the CNS. Neuron 20:749-761.

Isaacson JS, Walmsley B (1995) Counting quanta: direct measurements of transmitter release at a central synapse. Neuron 15:875-884.

Isaacson JS, Solis JM, Nicoll RA (1993) Local and diffuse synaptic actions of GABA in the hippocampus. Neuron 10:165-175.

Jack JJB, Noble D, Tsien RW (1983) Electric current flow in excitable cells. Oxford, UK: Oxford UP.

Kay LM, Laurent G (1999) Odor- and context-dependent modulation of mitral cell activity in behaving rats. Nat Neurosci 2:1003-1009.

Liao D, Hessler NA, Malinow R (1995) Activation of postsynaptically silent synapses during pairing-induced LTP in CA1 region of hippocampal slice. Nature 375:400-404.

Lledo PM, Alonso M, Grubb MS (2006) Adult neurogenesis and functional plasticity in neuronal circuits. Nat Rev Neurosci 7:179-193.

Lois C, Alvarez-Buylla A (1994) Long-distance neuronal migration in the adult mammalian brain. Science 264:1145-1148.

Malinow R, Malenka RC (2002) AMPA receptor trafficking and synaptic plasticity. Annu Rev Neurosci 25:103-126.

Nakashima M, Mori K, Takagi SF (1978) Centrifugal influence on olfactory bulb activity in the rabbit. Brain Res 154:301-306.

Oertner TG, Sabatini BL, Nimchinsky EA, Svoboda K (2002) Facilitation at single synapses probed with optical quantal analysis. Nat Neurosci 5:657-664.

Orona E, Rainer EC, Scott JW (1984) Dendritic and axonal organization of mitral and tufted cells in the rat olfactory bulb. J Comp Neurol 226:346-356.

Orth M, Bravo E, Barter L, Carstens E, Antognini JF (2006) The differential effects of halothane and isoflurane on electroencephalographic responses to electrical microstimulation of the reticular formation. Anesth Analg 102:1709-1714.

Petreanu L, Alvarez-Buylla A (2002) Maturation and death of adult-born olfactory bulb granule neurons: role of olfaction. J Neurosci 22:6106-6113.

Price JL, Powell TP (1970a) The synaptology of the granule cells of the olfactory bulb. J Cell Sci 7:125-155.

Price JL, Powell TP (1970b) An electron-microscopic study of the termination of the afferent fibres to the olfactory bulb from the cerebral hemisphere. J Cell Sci 7:157-187.

Rall W, Shepherd GM, Reese TS, Brightman MW (1966) Dendrodendritic synaptic pathway for inhibition in the olfactory bulb. Exp Neurol $14: 44-56$.

Ranck Jr JB (1975) Which elements are excited in electrical stimulation of mammalian central nervous system: a review. Brain Res 98:417-440.

Rinberg D, Koulakov A, Gelperin A (2006) Sparse odor coding in awake behaving mice. J Neurosci 26:8857-8865.

Rumpel S, LeDoux J, Zador A, Malinow R (2005) Postsynaptic receptor trafficking underlying a form of associative learning. Science 308:83-88.

Sassoe-Pognetto M, Ottersen OP (2000) Organization of ionotropic glutamate receptors at dendrodendritic synapses in the rat olfactory bulb. J Neurosci 20:2192-2201.

Schoppa NE, Urban NN (2003) Dendritic processing within olfactory bulb circuits. Trends Neurosci 26:501-506.

Schoppa NE, Westbrook GL (1999) Regulation of synaptic timing in the olfactory bulb by an A-type potassium current. Nat Neurosci 2:1106-1113

Schoppa NE, Kinzie JM, Sahara Y, Segerson TP, Westbrook GL (1998) Dendrodendritic inhibition in the olfactory bulb is driven by NMDA receptors. J Neurosci 18:6790-6802.

Shepherd GM, Greer CA (1998) Olfactory bulb. In: Synaptic organization of the brain, Ed 4 (Shepherd GM, ed), pp 159-204. New York: Oxford UP.

Shipley MT, Adamek GD (1984) The connections of the mouse olfactory bulb: a study using orthograde and retrograde transport of wheat germ agglutinin conjugated to horseradish peroxidase. Brain Res Bull 12:669-688.

Skeberdis VA, Chevaleyre V, Lau CG, Goldberg JH, Pettit DL, Suadicani SO, Lin Y, Bennett MV, Yuste R, Castillo PE, Zukin RS (2006) Protein kinase A regulates calcium permeability of NMDA receptors. Nat Neurosci 9:501-510.

Spruston N, Jaffe DB, Johnston D (1994) Dendritic attenuation of synaptic potentials and currents: the role of passive membrane properties. Trends Neurosci 17:161-166.

Uva L, Strowbridge BW, de Curtis M (2006) Olfactory bulb networks revealed by lateral olfactory tract stimulation in the in vitro isolated guinea pig brain. Neuroscience 142:567-577. 